\title{
Non-milk extrinsic sugars in the diets of pre-school children: association with intakes of micronutrients, energy, fat and NSP
}

\author{
BY SIGRID A. GIBSON \\ 21 Orchard Road, Burpham, Guildford GU4 7JH
}

(Received 20 August 1996 - Revised 21 January 1997 - Accepted 18 February 1997)

\begin{abstract}
Concern has been expressed that high dietary concentrations of non-milk extrinsic sugars (NMES) may potentially compromise nutrient intakes in population groups with low energy intakes (Department of Health, 1991). The objective of the present study was to examine data from the National Diet and Nutrition Survey of Children Aged 1.5 to 4.5 years (Gregory et al. 1995) for evidence of an inverse association between energy from NMES and micronutrient intakes, and if possible to quantify a level of NMES-energy at which micronutrient intakes may, theoretically, be compromised. Energy and nutrient intakes were compared across quintiles of NMES-energy for boys ( $n$ 848) and girls ( $n$ 827). As the concentration of NMES increased, energy intake rose (in boys only) while percentage energy from fat fell from 40 to $32 \%$ across quintiles 1 to 5 . Intakes of most micronutrients also fell, while intakes of vitamin $\mathrm{C}$ rose. Mean intakes of most micronutrients $(\mathrm{Ca}$, thiamin, riboflavin, niacin, folate and vitamin $\mathrm{C}$ ) were adequate in comparison with dietary reference values. However, intakes of $\mathrm{Fe}, \mathrm{Zn}$ and vitamin $\mathrm{D}$ were low at all levels of NMES-energy and fell below the estimated average requirement for $\mathrm{Fe}$ and $\mathrm{Zn}$ for NMES concentrations exceeding $24 \%$ of energy. Lower intakes of milk, meat, bread and vegetables, and higher intakes of fruit juice largely explain the observed trends in micronutrient intake. It is concluded that the inverse association of NMES with micronutrient intakes is of most significance for the $20 \%$ of children with diets highest in NMES. However, further work is required to establish whether the associations observed have biological significance with regard to micronutrient status.
\end{abstract}

Non-milk extrinsic sugars: Micronutrient intake: Children

The term 'non-milk extrinsic sugars' (NMES) was first coined by the Committee on Medical Aspects of Food Policy (COMA) Panel on Dietary Sugars (Department of Health and Social Security, 1989). This was an attempt to define a subclass of sugars whose limitation in the diet was considered desirable on grounds of dental caries, yet without compromise to nutrient intake. The definition NMES includes all sugars that are neither components of milk, nor contained within plant cell walls. Thus, it includes table sugar, sugars and syrups used in processing, honey, and sugars in fruit juices. NMES comprise about two-thirds of dietary sugars and contribute about $19 \%$ of the total dietary energy in young children (Gregory et al. 1995).

Dietary guidelines have emphasized limiting the intake of NMES primarily on grounds of their putative contribution to dental caries and obesity. However, it has also been suggested that relatively high intakes of NMES may compromise micronutrient intake in individuals with low energy requirements and intakes (Department of Health, 1991). Elderly people, and women, were cited as examples, but children may arguably be in this category also. Their requirements of certain nutrients (e.g. Fe, $\mathrm{Zn}$, vitamin $\mathrm{C}$ and vitamin A) are higher, relative to their energy needs, than those of some adults. 
Several studies have examined the concept of nutrient dilution by sugars, variously defined, in the diets of schoolchildren (Nelson et al. 1990; Rugg-Gunn et al. 1991; Gibson, 1993; Naismith et al. 1995). However, there has been no nationwide government dietary survey of the pre-school age group since 1967-8 (Department of Health and Social Security, 1975). The National Diet and Nutrition Survey (Gregory et al. 1995) provides an opportunity to assess the relationship between NMES consumption and nutrient intakes and its significance in the diets of this potentially vulnerable group.

The objectives of the present study were to examine data from the National Diet and Nutrition Survey of Children Aged 1.5 to 4.5 Years (NDNS; Gregory et al. 1995) (a) for evidence of an inverse association between NMES concentration and intakes of micronutrients; (b) to examine trends in energy, fat and NSP intakes across NMES quintiles, and (c) to compare micronutrient uptakes with appropriate dietary reference values (DRV; Department of Health, 1991).

\section{METHODS}

Computer files of the dietary and questionnaire information from the NDNS were obtained from the National Data Archive at the University of Essex. These contained data on the average daily intake of nutrients, as calculated from the $4 \mathrm{~d}$ weighed records, of 1675 boys and girls aged between 1.5 and 4.5 years. The sample was designed to be nationally representative with regard to region and socio-economic status. For the present investigation, ANOVA was chosen, rather than a regression technique, because it demonstrates better any threshold effect and is well-suited to a graphical presentation of results. The 848 boys and 827 girls were classified into quintiles (fifths) on the basis of their intake of NMES (as a percentage of energy; NMES-energy). Quintile cut-off points (20th, 40th, 60th and 80th percentiles) and summary statistics for each sex are given in Table 1 . The first quintile refers to the group whose upper bound is the 20th percentile. Differences between quintiles were compared by one-way ANOVA, with post-hoc comparisons by the Bonferroni (modified least significant difference) test. Kruskal-Wallis (non-parametric) ANOVA was used for vitamin D.

\section{RESULTS}

Fig. 1 shows the distribution of NMES intakes for boys and girls. Tables 2 and 3 show the mean intakes of micronutrients by quintile of NMES-energy, the overall significance of

Table 1. Mean intakes of non-milk extrinsic sugars (NMES) as a percentage of energy, and quintile cut-off points for the five groups

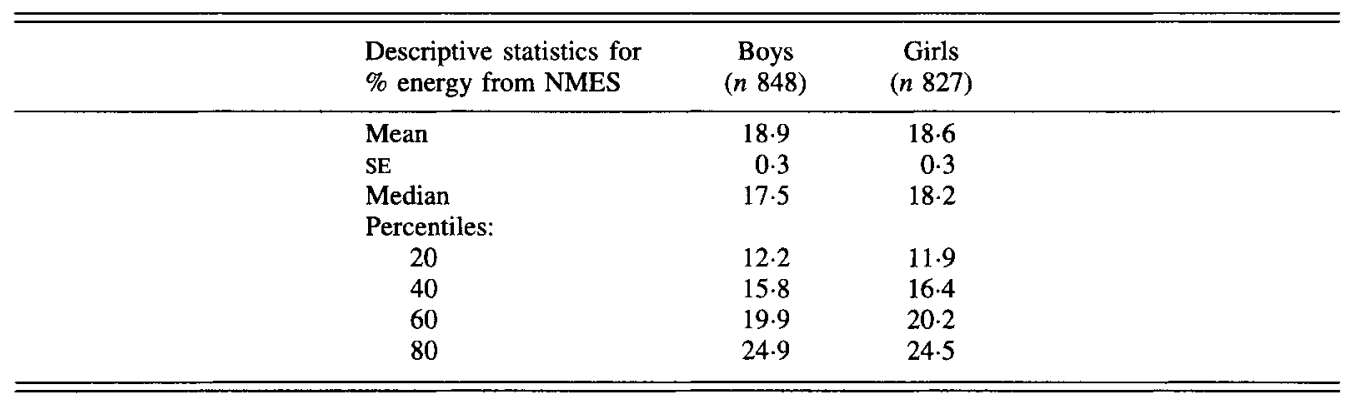



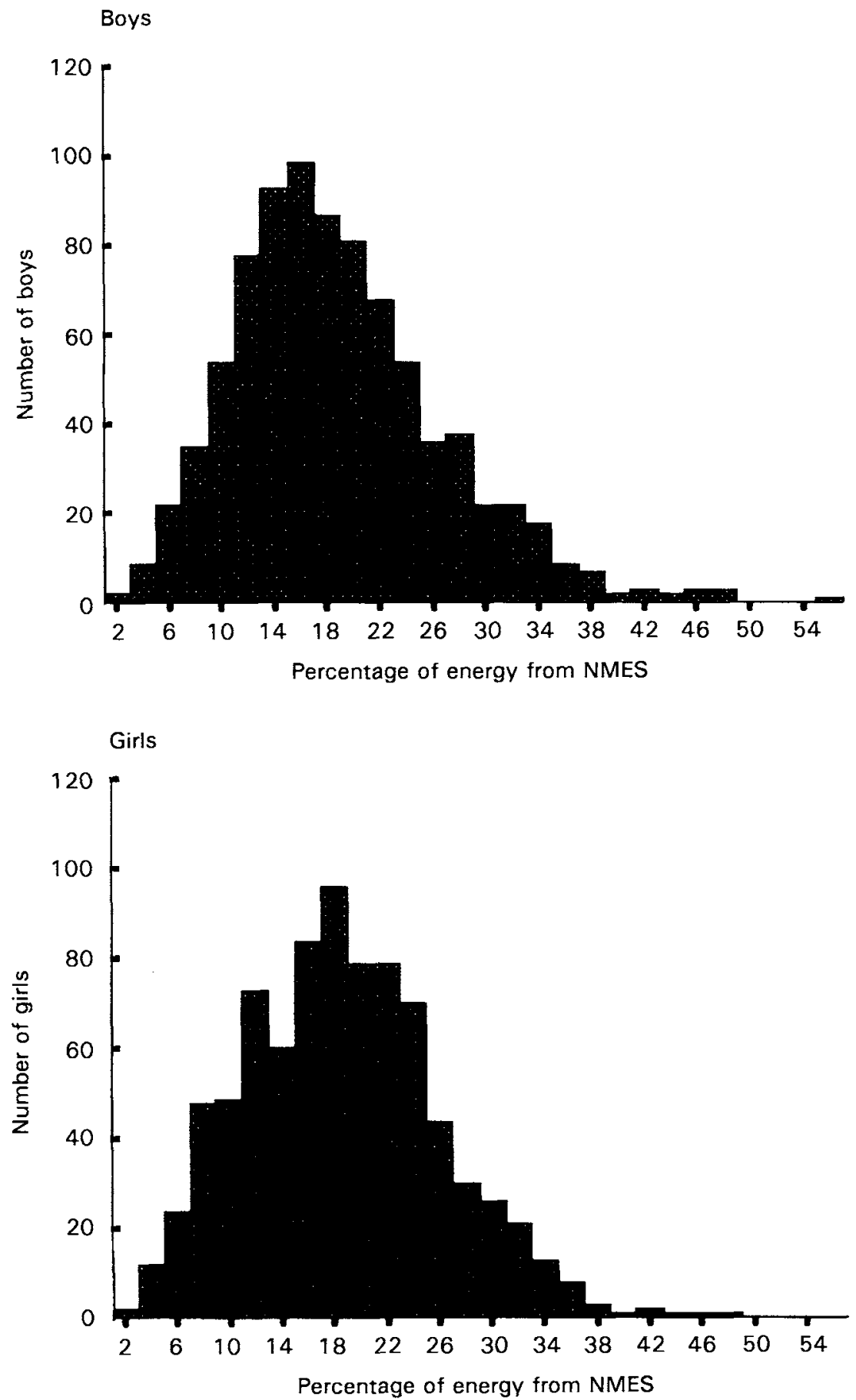

Fig. 1. Distribution of intakes of non-milk extrinsic sugars (NMES) energy for boys and girls aged 1-5-4.5 years. Mean values were: boys 18.9 (SD 8)\%, girls 18.6 (SD 7.5)\%. 
Table 2. Micronutrient intakes by quintile of non-milk extrinsic sugars energy (boys)

\begin{tabular}{|c|c|c|c|c|c|c|c|c|}
\hline & & \multicolumn{5}{|c|}{ Quintiles of \% energy from non-milk extrinsic sugars } & \multirow[b]{2}{*}{$\begin{array}{c}\text { ANOVA } \\
P=\end{array}$} & \multirow[b]{2}{*}{$\begin{array}{l}\text { All boys } \\
(n 848)\end{array}$} \\
\hline & & $\begin{array}{c}1 \\
(n 169)\end{array}$ & $\begin{array}{c}2 \\
(n 170)\end{array}$ & $\begin{array}{c}3 \\
(n 170)\end{array}$ & $\begin{array}{c}4 \\
(n 170)\end{array}$ & $\begin{array}{c}5 \\
\text { (n 169) }\end{array}$ & & \\
\hline \multirow{2}{*}{$\begin{array}{l}\text { Energy } \\
\qquad(\mathrm{kJ} / \mathrm{d})\end{array}$} & Mean & $4724^{a}$ & $4890^{\mathrm{ab}}$ & $4970^{\mathrm{ab}}$ & $4974^{\mathrm{ab}}$ & $5093^{b}$ & 0.033 & 4930 \\
\hline & $\mathrm{SE}$ & 84 & 78 & 84 & 86 & 86 & & 38 \\
\hline \multirow{2}{*}{$\begin{array}{l}\text { Calcium } \\
(\mathrm{mg} / \mathrm{d})\end{array}$} & Mean & $798^{\mathrm{d}}$ & $666^{\mathrm{bc}}$ & $679^{c}$ & $597^{b}$ & $517^{\mathrm{a}}$ & $<0.0001$ & 651 \\
\hline & $\mathrm{SE}$ & 23 & 18 & 19 & 16 & 14 & & 9 \\
\hline \multirow{2}{*}{$\begin{array}{l}\text { Iron } \\
\qquad(\mathrm{mg} / \mathrm{d})\end{array}$} & Mean & $5 \cdot 7^{\mathrm{ab}}$ & $6 \cdot 1^{\mathrm{b}}$ & $5 \cdot 7^{\mathrm{ab}}$ & $5 \cdot 8^{\mathrm{b}}$ & $5 \cdot 1^{\mathrm{a}}$ & 0.0018 & 5.7 \\
\hline & SE & 0.2 & 0.2 & 0.2 & 0.2 & 0.1 & & 0.1 \\
\hline \multirow{2}{*}{$\begin{array}{l}\text { Zinc } \\
(\mathrm{mg} / \mathrm{d})\end{array}$} & Mean & $5 \cdot 2^{\mathrm{c}}$ & $4 \cdot 7^{b}$ & $4.5^{b}$ & $4.4^{b}$ & $3.7^{\mathrm{a}}$ & $<0.0001$ & 4.5 \\
\hline & SE & 0.1 & 0.1 & 0.1 & 0.1 & 0.1 & & 0.1 \\
\hline \multirow{2}{*}{$\begin{array}{l}\text { Thiamin } \\
\text { (mg/d) }\end{array}$} & Mean & $0.87^{\mathrm{b}}$ & $0.86^{b}$ & $0.85^{b}$ & $0.80^{\mathrm{ab}}$ & $0.73^{a}$ & $<0.0001$ & 0.82 \\
\hline & $\mathrm{SE}$ & 0.02 & 0.02 & 0.02 & 0.02 & $0 \cdot 02$ & & 0.01 \\
\hline \multirow{2}{*}{$\begin{array}{l}\text { Riboflavin } \\
\text { (mg/d) }\end{array}$} & Mean & $1.43^{\mathrm{c}}$ & $1.28^{b}$ & $1.27^{b}$ & $1 \cdot 18^{b}$ & $1 \cdot 01^{\mathrm{a}}$ & $<0.0001$ & 1.23 \\
\hline & SE & 0.04 & 0.04 & 0.03 & 0.03 & 0.03 & & 0.02 \\
\hline \multirow{2}{*}{$\begin{array}{l}\text { Niacin equivalents } \\
(\mathrm{mg} / \mathrm{d})\end{array}$} & Mean & $17 \cdot 4^{\mathrm{b}}$ & $17 \cdot 1^{\mathrm{b}}$ & $16 \cdot 8^{b}$ & $16 \cdot 3^{\mathrm{ab}}$ & $15 \cdot 2^{\mathrm{a}}$ & 0.0005 & $16 \cdot 6$ \\
\hline & $\mathrm{SE}$ & 0.4 & 0.3 & 0.4 & 0.4 & 0.4 & & 0.2 \\
\hline \multirow{2}{*}{$\begin{array}{l}\text { Folate } \\
\qquad(\mu \mathrm{g} / \mathrm{d})\end{array}$} & Mean & $136^{\mathrm{a}}$ & $141^{\mathrm{a}}$ & $136^{\mathrm{a}}$ & $128^{\mathrm{a}}$ & $126^{\mathrm{a}}$ & 0.032 & 133 \\
\hline & SE & 4 & 4 & 4 & 3 & 4 & & 2 \\
\hline \multirow{2}{*}{$\begin{array}{c}\text { Vitamin C } \\
(\mathrm{mg} / \mathrm{d})\end{array}$} & Mean & $36^{a}$ & $44^{a}$ & $48^{a}$ & $54^{b}$ & $71^{\mathrm{c}}$ & $<0.0001$ & 51 \\
\hline & SE & 2 & 2 & 3 & 3 & 5 & & 1 \\
\hline \multirow{2}{*}{$\begin{array}{l}\text { Vitamin D } \\
(\mu \mathrm{g} / \mathrm{d})\end{array}$} & Mean & $2 \cdot 1$ & 1.8 & 1.8 & 1.6 & 1.8 & $0.022 *$ & 1.8 \\
\hline & $\mathrm{SE}$ & 0.2 & 0.2 & 0.1 & 0.1 & 0.2 & & 0.1 \\
\hline
\end{tabular}

${ }^{\text {a,b,c }}$ Mean values within a row not sharing a common superscript letter were significantly different, $P<0.05$ (multiple range test).

* Kruskal-Wallis non-parametric ANOVA.

differences between the quintiles (assessed by ANOVA) and a multiple range test for evaluation of inter-group differences. Figs. 2-4 identify the shape of the NMESmicronutrient relationship and its relevance in terms of DRV; a reference line corresponding to the reference nutrient intake (RNI), or the estimated average requirement (EAR) (Department of Health, 1991) where intakes were low, has been superimposed for this purpose.

There was little difference in energy intakes across quintiles for girls, although in boys there was a $369 \mathrm{~kJ}$ difference (approximately $8 \%$ ) between the lowest and highest NMES quintiles $(P<0.05)$. As the concentration of NMES rose, there was a significant reduction in mean intake of most micronutrients $(\mathrm{Ca}, \mathrm{Zn}$, thiamin, riboflavin, niacin; $P<0.001)$. Vitamin $C$ intakes, by contrast, were positively associated with NMES $(P<0.0001)$, reflecting fruit juice consumption. In boys, for example, the mean vitamin $C$ intake in quintile $5(71 \mathrm{mg} / \mathrm{d})$ was nearly double that in quintile $1(36 \mathrm{mg} / \mathrm{d})$.

Fe intakes in boys fell with increasing NMES intake $(P=0.0018)$ but this was not significant in girls $(P=0 \cdot 30)$. Moreover, the trend in boys was non-linear, with significant decline only at the top quintile ( $>24 \%$ energy from NMES). There was little evidence of the 'n-shaped' relationship observed in some adult studies (Gibney et al. 1995; Gibson 1997). The latter may reflect under-reporting or under-eating in the low-sugar group, a phenomenon not observed in these children.

Percentage energy from fat, and also NSP density, were strongly inversely associated with NMES concentration $(P<0.0001$; Table 4$)$.

One important objective of this study was to evaluate micronutrient intakes across NMES quintiles, using DRV. This is illustrated in Figs. 2-4. With the exception of Fe, $\mathrm{Zn}$ 
Table 3. Micronutrient intakes by quintile of non-milk extrinsic sugars energy (girls)

\begin{tabular}{|c|c|c|c|c|c|c|c|c|}
\hline & & \multicolumn{5}{|c|}{ Quintiles of \% energy from non-milk extrinsic sugars } & \multirow[b]{2}{*}{$\begin{array}{c}\text { ANOVA } \\
P=\end{array}$} & \multirow[b]{2}{*}{$\begin{array}{l}\text { All girls } \\
(n \text { 827) }\end{array}$} \\
\hline & & $\begin{array}{c}1 \\
(n 166)\end{array}$ & $\begin{array}{c}2 \\
(n 165)\end{array}$ & $\begin{array}{c}3 \\
n 166)\end{array}$ & $\begin{array}{c}4 \\
(n 165)\end{array}$ & $\begin{array}{c}5 \\
(n 165)\end{array}$ & & \\
\hline \multirow{2}{*}{$\begin{array}{l}\text { Energy } \\
\qquad(\mathrm{kJ} / \mathrm{d})\end{array}$} & Mean & 4590 & 4615 & 4767 & 4668 & 4673 & NS & 4663 \\
\hline & SE & 89 & 80 & 82 & 79 & 83 & & 37 \\
\hline \multirow{2}{*}{$\begin{array}{l}\text { Calcium } \\
(\mathrm{mg} / \mathrm{d})\end{array}$} & Mean & $769^{d}$ & $668^{\mathrm{c}}$ & $615^{b c}$ & $566^{\mathrm{ab}}$ & $501^{a}$ & $<0.0001$ & 624 \\
\hline & SE & 24 & 19 & 17 & 14 & 16 & & 9 \\
\hline \multirow{2}{*}{$\begin{array}{l}\text { Iron } \\
(\mathrm{mg} / \mathrm{d})\end{array}$} & Mean & $5 \cdot 4^{\mathrm{a}}$ & $5 \cdot 6^{\mathrm{a}}$ & $5 \cdot 6^{\mathrm{a}}$ & $5 \cdot 3^{\mathrm{a}}$ & $5 \cdot 1^{\mathrm{a}}$ & NS & 5.4 \\
\hline & $\mathrm{SE}$ & 0.2 & 0.2 & 0.2 & 0.2 & 0.2 & & 0.1 \\
\hline \multirow{2}{*}{$\begin{array}{l}\text { Zinc } \\
\quad(\mathrm{mg} / \mathrm{d})\end{array}$} & Mean & $5 \cdot 0^{\mathrm{d}}$ & $4 \cdot 6^{\mathrm{c}}$ & $4 \cdot 3^{b c}$ & $4 \cdot 0^{a b}$ & $3 \cdot 7^{\mathrm{a}}$ & $<0.0001$ & $4 \cdot 3$ \\
\hline & SE & 0.1 & 0.1 & 0.1 & 0.1 & 0.1 & & 0.1 \\
\hline \multirow{2}{*}{$\begin{array}{l}\text { Thiamin } \\
(\mathrm{mg} / \mathrm{d})\end{array}$} & Mean & $0.85^{\mathrm{b}}$ & $0.87^{b}$ & $0.79^{\mathrm{ab}}$ & $0.78^{\mathrm{ab}}$ & $0.73^{\mathrm{a}}$ & 0.0009 & 0.81 \\
\hline & SE & 0.03 & 0.03 & 0.02 & 0.02 & 0.03 & & 0.01 \\
\hline \multirow{2}{*}{$\begin{array}{l}\text { Riboflavin } \\
(\mathrm{mg} / \mathrm{d})\end{array}$} & Mean & $1 \cdot 37^{\mathrm{c}}$ & $1.28^{\mathrm{bc}}$ & $1.15^{\mathrm{ab}}$ & $1 \cdot 10^{\mathrm{a}}$ & $1.03^{\mathrm{a}}$ & $<0.0001$ & 1.19 \\
\hline & SE & 0.04 & 0.03 & 0.03 & 0.03 & 0.03 & & 0.02 \\
\hline \multirow{2}{*}{$\begin{array}{l}\text { Niacin equivalents } \\
(\mathrm{mg} / \mathrm{d})\end{array}$} & Mean & $17 \cdot 1^{\mathrm{b}}$ & $16 \cdot 8^{\mathrm{b}}$ & $15 \cdot 9^{\mathrm{ab}}$ & $15 \cdot 8^{\mathrm{ab}}$ & $14 \cdot 9^{a}$ & 0.0006 & $16 \cdot 1$ \\
\hline & SE & 0.4 & 0.4 & 0.4 & 0.4 & 0.4 & & 0.2 \\
\hline \multirow{2}{*}{$\begin{array}{l}\text { Folate } \\
\qquad(\mu \mathrm{g} / \mathrm{d})\end{array}$} & Mean & $135^{\mathrm{b}}$ & $137^{b}$ & $131^{\mathrm{ab}}$ & $128^{a b}$ & $119^{a}$ & 0.006 & 130 \\
\hline & SE & 4 & 3 & 4 & 4 & 4 & & 2 \\
\hline \multirow{2}{*}{$\begin{array}{l}\text { Vitamin C } \\
(\mathrm{mg} / \mathrm{d})\end{array}$} & Mean & $42^{\mathrm{a}}$ & $46^{\mathrm{a}}$ & $51^{\mathrm{a}}$ & $54^{\mathrm{a}}$ & $72^{\mathrm{b}}$ & $<0.0001$ & 53 \\
\hline & $\mathrm{SE}$ & 2 & 2 & 3 & 3 & 5 & & 2 \\
\hline \multirow{2}{*}{$\begin{array}{l}\text { Vitamin D } \\
(\mu \mathrm{g} / \mathrm{d})\end{array}$} & Mean & $2 \cdot 2$ & $2 \cdot 3$ & 1.7 & 1.9 & 1.8 & NS* & $2 \cdot 0$ \\
\hline & $\mathrm{SE}$ & 0.2 & 0.2 & 0.1 & 0.2 & 0.2 & $(P=0.08)$ & $0 \cdot 1$ \\
\hline
\end{tabular}

a.b.c.d Mean values within a row not sharing a common superscript letter were significantly different, $P<0.05$ (multiple range test).

* Kruskal-Wallis non-parametric ANOVA.

Table 4. Mean NSP density and percentage energy from fat, by quintile of non-milk extrinsic sugars energy intake in boys and girls

\begin{tabular}{llccccccc}
\hline \multicolumn{7}{c}{ Quintiles of \% energy from non-milk extrinsic } \\
sugars
\end{tabular}

a,b,c,d,e Mean values within a row not sharing a common superscript letter were significantly different, $P<0.05$. 
Boys

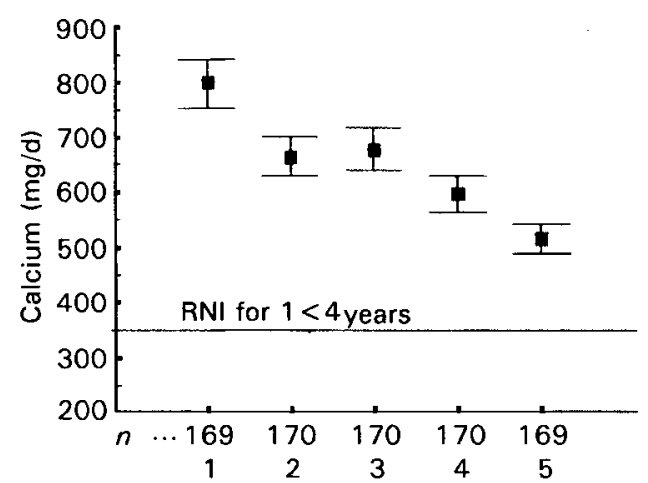

Quintile of NMES (\% of energy)

Boys

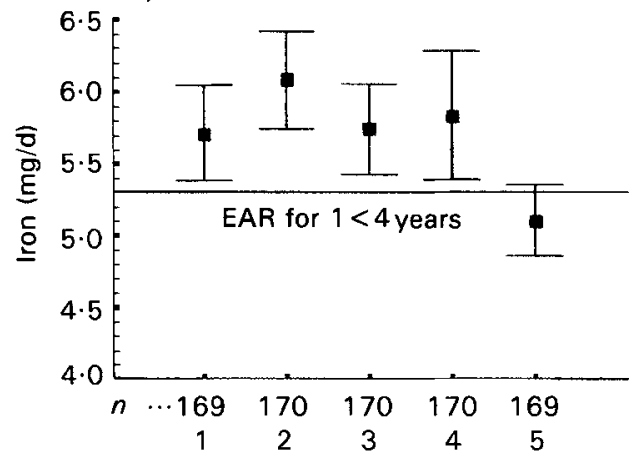

Quintile of NMES (\% of energy)

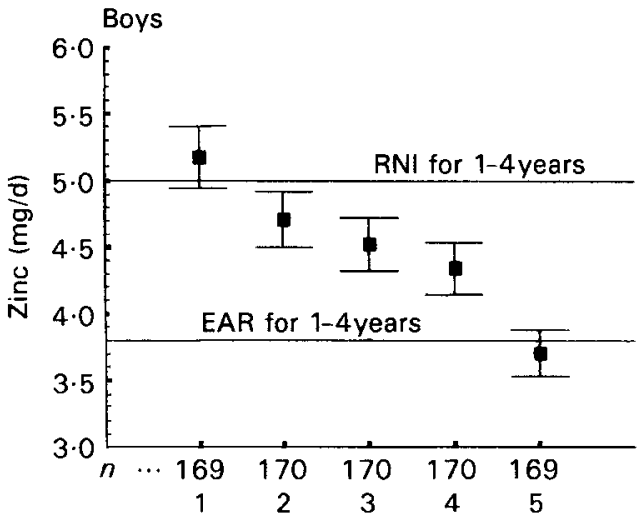

Quintile of NMES (\% of energy)

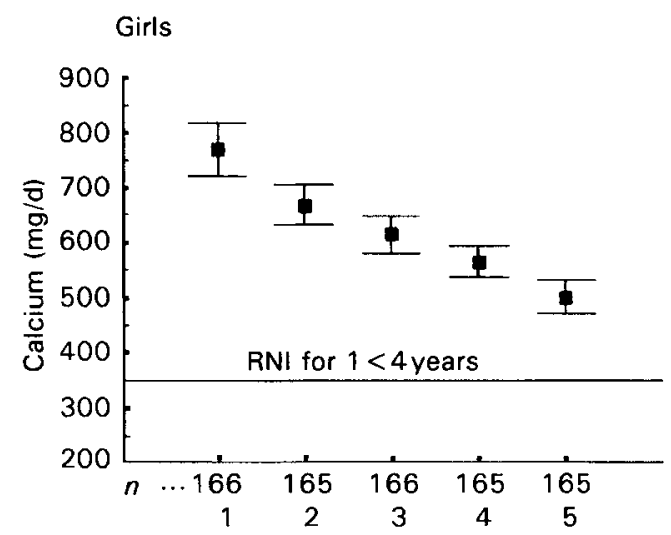

Quintile of NMES (\% of energy)

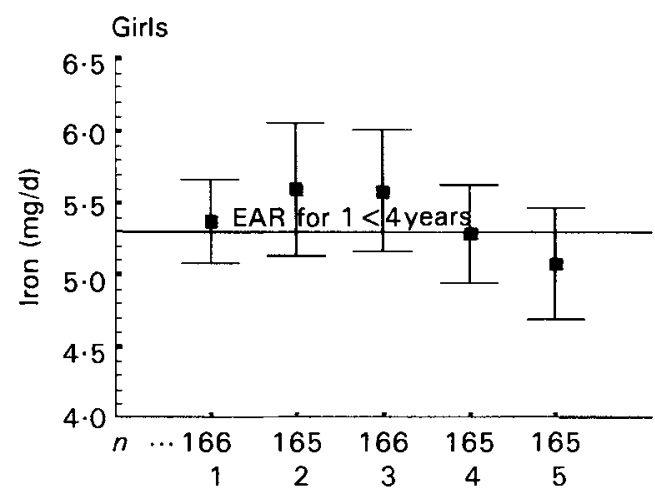

Quintile of NMES (\% of energy)

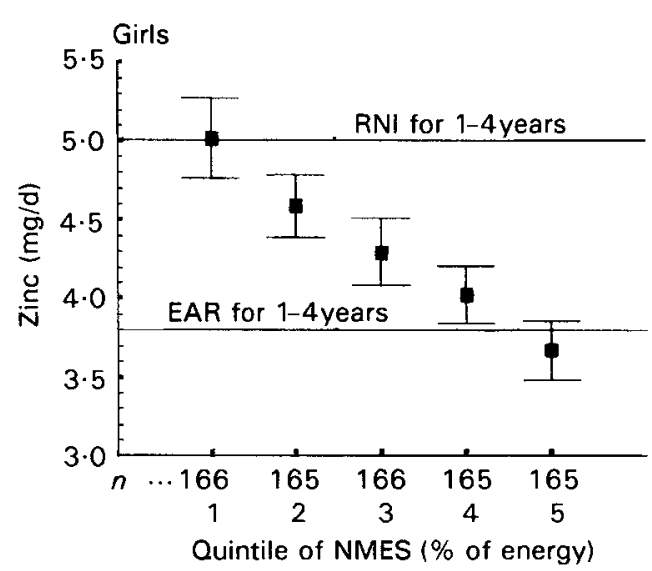

Fig. 2. Intakes of calcium, iron and zinc by quintile of non-milk extrinsic sugars (NMES) energy intake in boys and girls aged $1.5-4.5$ years. Values are means and $95 \%$ confidence intervals. RNI, reference nutrient intake; EAR, estimated average requirement (Department of Health, 1991). 

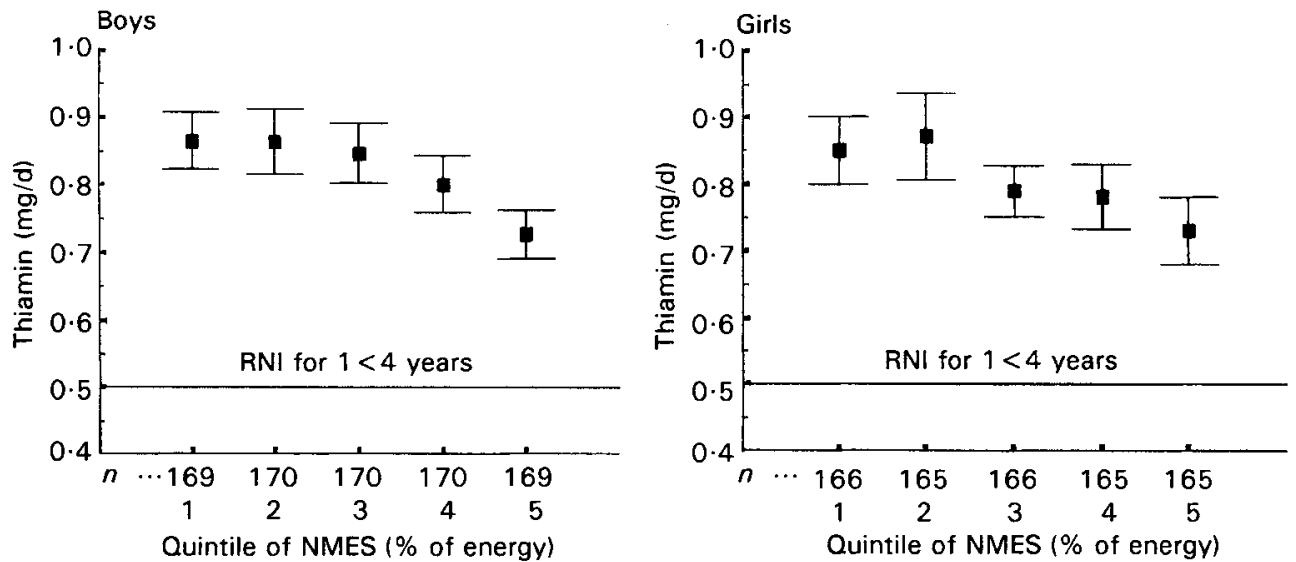

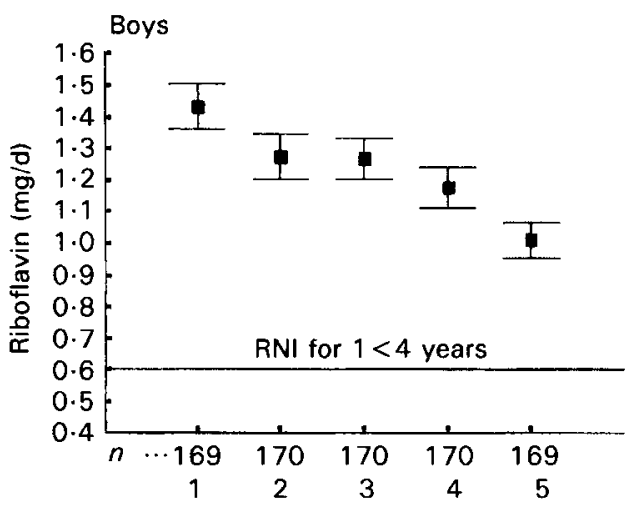

Quintile of NMES (\% of energy)

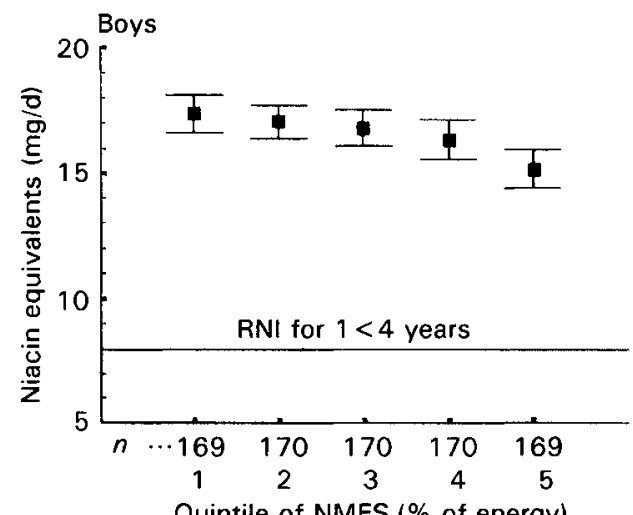

Quintile of NMES (\% of energy)

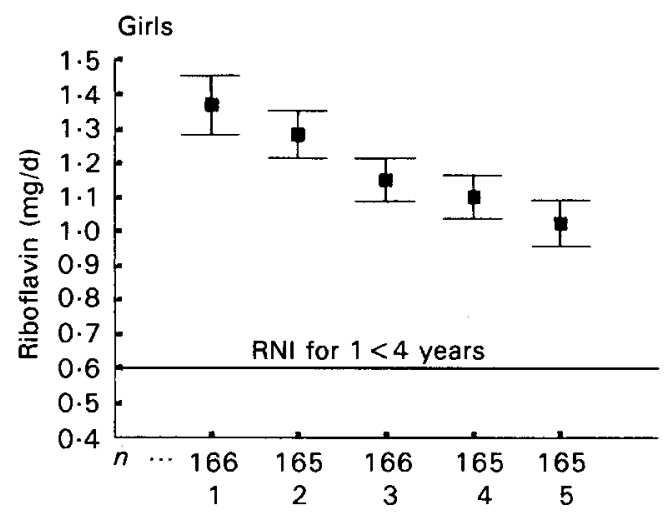

Quintile of NMES ( $\%$ of energy)

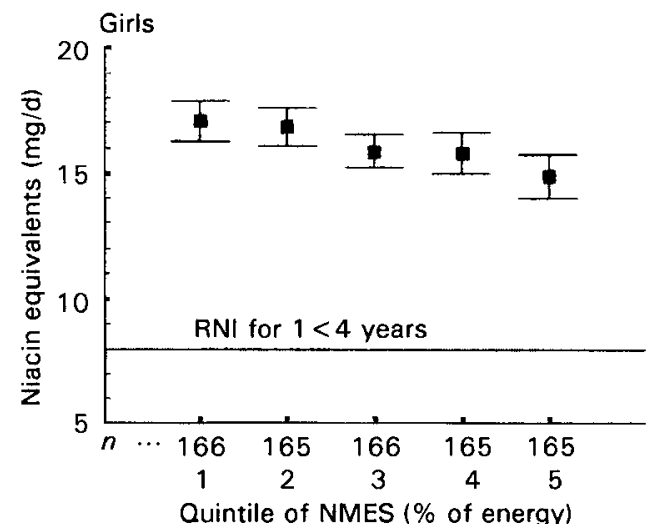

Fig. 3. Intakes of thiamin, riboflavin and niacin by quintile of non-milk extrinsic sugars (NMES) energy intake in boys and girls aged 1.5-4.5 years. Values are means and $95 \%$ confidence intervals. RNI, reference nutrient intake (Department of Health, 1991). 


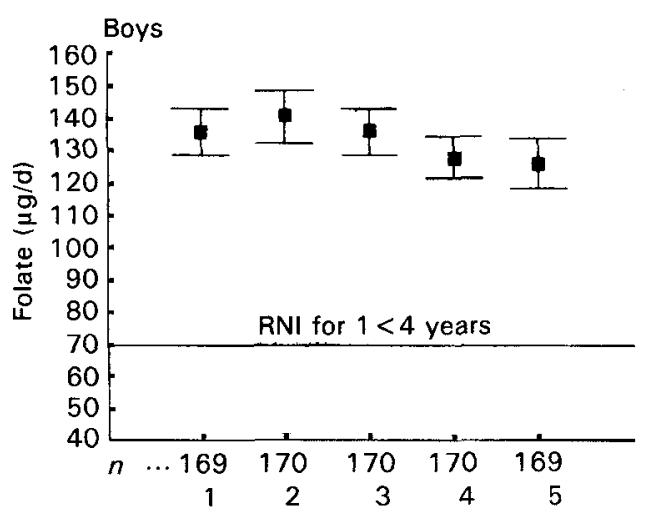

Quintile of NMES (\% of energy)
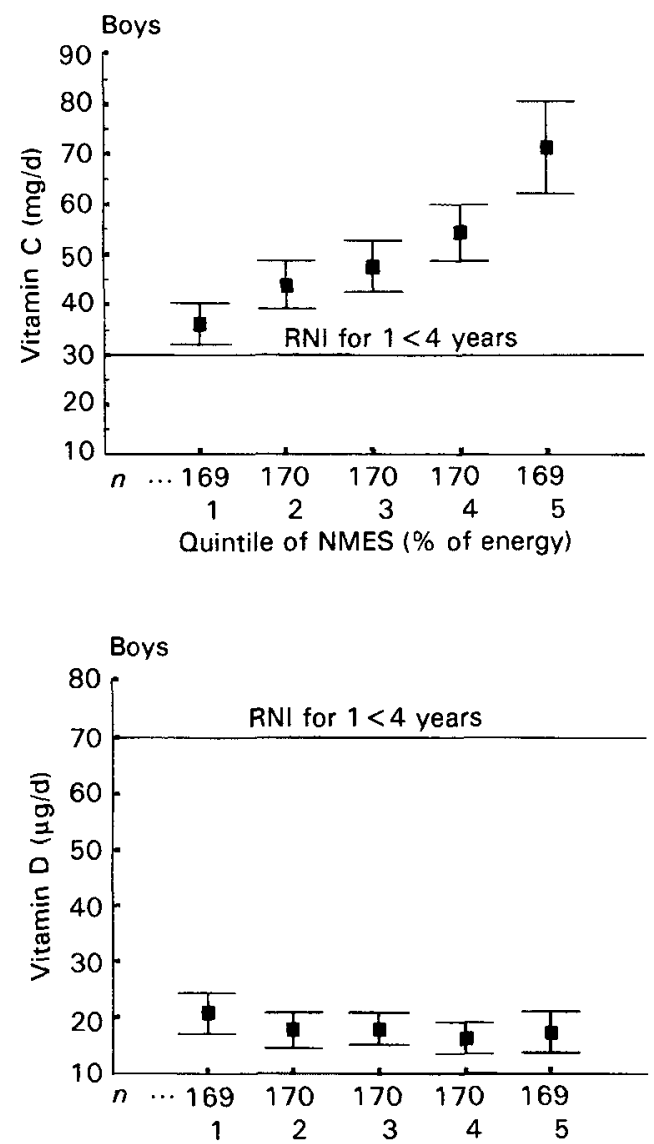

Quintile of NMES (\% of energy)

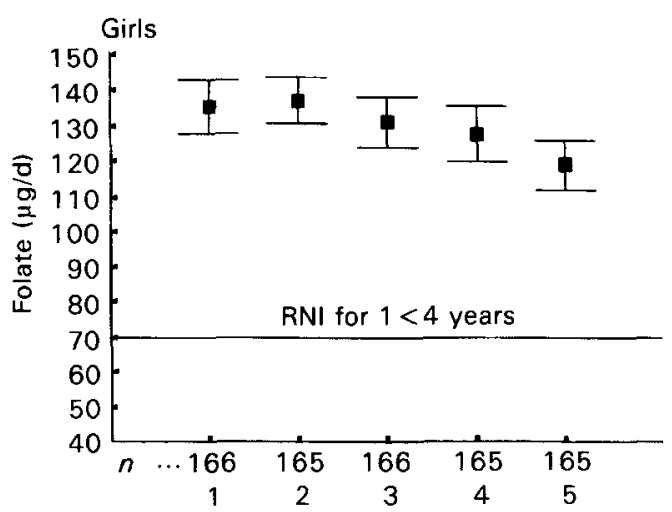

Quintile of NMES (\% of energy)
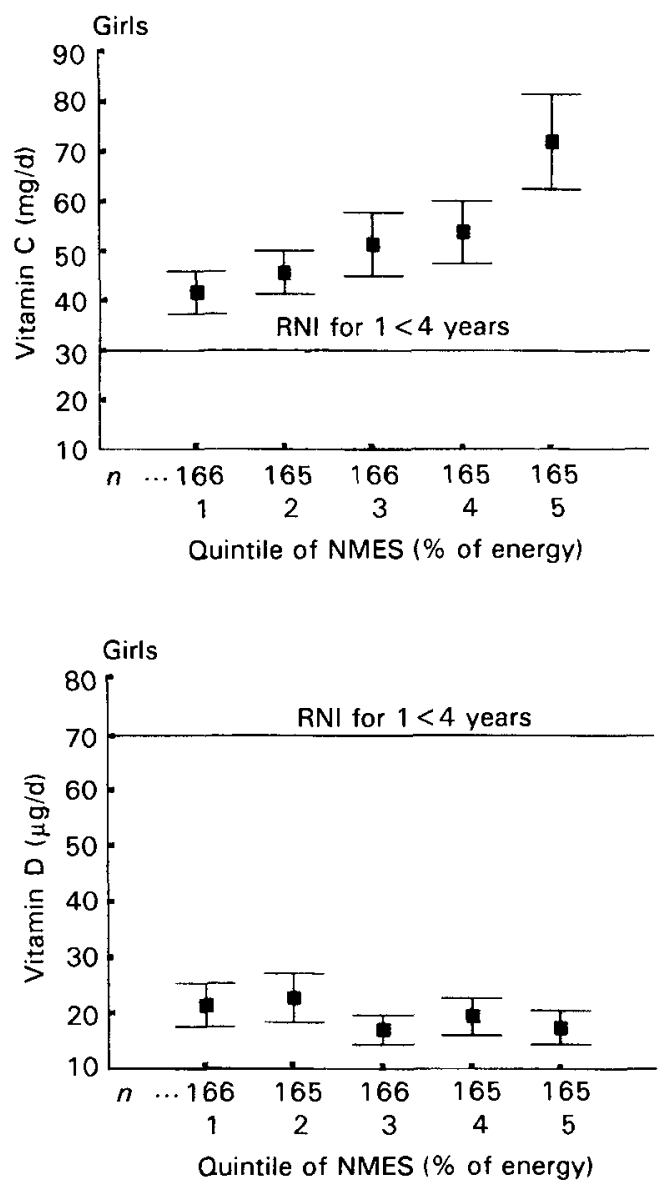

Fig. 4. Intakes of folate, vitamin $\mathrm{C}$ and vitamin $\mathrm{D}$ by quintile of non-milk extrinsic sugars (NMES) energy intake in boys and girls aged $1 \cdot 5-4.5$ years. Values are means and $95 \%$ confidence intervals. RNI, reference nutrient intake (Department of Health, 1991). 
Table 5. Intakes of various food groups by quintile of non-milk extrinsic sugars energy in boys and girls (sexes combined)

\begin{tabular}{lcccccc}
\hline & & \multicolumn{5}{c}{ Quintile } \\
\cline { 3 - 7 } Consumption (g/week) & Mean & 1 & 2 & 3 & 4 & 5 \\
\hline Milk (litres/week) & $2 \cdot 1$ & $3 \cdot 1$ & $2 \cdot 2$ & $2 \cdot 0$ & $1 \cdot 7$ & $1 \cdot 2$ \\
Meat and meat products & 362 & 395 & 383 & 367 & 351 & 313 \\
Breakfast cereals & 137 & 132 & 152 & 146 & 135 & 122 \\
Bread & 282 & 305 & 285 & 300 & 280 & 238 \\
Vegetables & 610 & 674 & 657 & 641 & 566 & 512 \\
Fruit juice & 258 & 146 & 202 & 299 & 275 & 370 \\
Soft drinks (litres/week) & 1.8 & 0.5 & $1 \cdot 1$ & 1.5 & $2 \cdot 2$ & 3.7 \\
Confectionery & 142 & 61 & 99 & 137 & 178 & 234 \\
\hline \hline
\end{tabular}

* Excluding low-energy soft drinks.

and vitamin $\mathrm{D}$, mean intakes were more than adequate in all NMES quintiles. Fe and $\mathrm{Zn}$ intakes were marginal at all levels of NMES, suggesting that the problem of potential dietary inadequacy is a general one, rather than related principally to sugars consumption. Nevertheless, for children with low energy intakes, high NMES diets ( $>24 \%$ of energy as NMES) may potentiate the risk of inadequate nutrient intakes.

To explore possible reasons for differences in nutrient intakes between the quintiles, differences in food consumption across the quintiles were examined (Table 5). Children in the lowest NMES quintile were significantly younger (mean age 32 months compared with the average across all groups of 35 months; $P<0.0001$ ), but mean ages did not differ across quintiles 2 to 5 . Children with diets highest in NMES (i.e. 5th quintile or $>24 \%$ energy from NMES) consumed about twice the average quantity of confectionery and soft drinks. They also drank more fruit juice. Milk consumption was lower ( 1.2 litres/week $v$. average of $2 \cdot 1$ litres/week), and they ate less meat, bread, cereals and vegetables, especially leafy green vegetables. The tendency to lower consumption of these nutrientdense foods in the higher NMES quintiles is a likely explanation for the observed trends in micronutrient intakes.

\section{DISCUSSION}

Relationships between dietary sugars concentration and micronutrient intakes have previously been reported for adults and for children of school age, but not to our knowledge for British children under 5 years. Some studies have found a small nutrient dilution effect of high concentrations of sugars, but not all reached conventional levels of significance (Department of Health and Social Security, 1989; Nelson et al. 1990; RuggGunn et al. 1991; Gibson, 1993; Naismith et al. 1995). The smaller studies have sometimes lacked the statistical power to demonstrate significant associations, because the effect under investigation is relatively small. Studies that have examined intakes by quintiles of NMES, or of total sugars, have tended to show that micronutrient intakes are highest at 'moderate' or average levels of consumption (Bolton-Smith \& Woodward, 1994; Gibney et al. 1995; Gibson, 1997; S. Gatenby, unpublished results). These studies suggest that NMES intakes up to about $16 \%$ of energy are not associated with compromised nutrient intakes, and confirm that 'sugars intake is a weaker predictor of absolute micronutrient intakes than total energy consumption' (Department of Health and Social Security, 1989). 
In the present investigation of data from the National Diet and Nutrition Survey of Children Aged 1.5 to 4.5 Years, NMES provided on average $18.7 \%$ of total energy. This is very similar to the value $(18.4 \%)$ calculated from the previous Department of Health survey of this same age group in 1967-8 (Department of Health and Social Security, 1975, 1989). It is substantially higher than the estimates for the whole population from the National Food Survey (approximately 13\%; Department of Health, 1994) and for adults in the Dietary and Nutritional Survey of British Adults (Gregory et al. 1990) (approximately $16 \%$; Department of Health, 1994). High NMES intakes, coupled with the large sample size of the NDNS, mean that if an effect of NMES concentration is present, it should be detectable in the present analysis.

The results of the present analyses indicate some evidence of nutrient dilution. Children consuming the highest concentrations of NMES (5th quintile or $>24 \%$ energy) had intakes of most micronutrients that were between 6 and $20 \%$ below average. By contrast, their vitamin $\mathrm{C}$ intakes were between 36 and $40 \%$ higher than average.

In comparison with DRV, group intakes were more than adequate for most nutrients. The notable exceptions were Fe, $\mathrm{Zn}$ and vitamin $\mathrm{D}$, which were below or close to the EAR across all quintiles. Low Fe intakes have also been reported in a Scottish study of 2-5-yearolds (Payne \& Belton, 1992) and also in older children (Department of Health and Social Security, 1989; Nelson et al. 1990) but intakes in a recent survey of 7-8-year-olds in Edinburgh were found to be adequate (Ruxton et al. 1996). In the present survey Fe intake was of most concern, since the haematological analyses indicated that $8 \%$ of children had haemoglobin levels below $110 \mathrm{~g} / \mathrm{l}$, and $20 \%$ had serum ferritin levels below $10 \mu \mathrm{g} / 1$ (Gregory et al. 1995). Fe status is influenced by a number of factors, dietary ones including the form in which $\mathrm{Fe}$ is consumed and the presence of enhancing or inhibiting components. Enhanced $\mathrm{Fe}$ bioavailability arising from the high vitamin $\mathrm{C}$ intakes in the high NMES groups may have compensated for the small dilution effect of NMES on Fe intake (significant only in boys). It is relevant that levels of serum ferritin and haemoglobin did not differ significantly across NMES quintiles.

The present study, and those by Payne \& Belton (1992) and Ruxton et al. (1996), all found $\mathrm{Zn}$ intakes to be marginal in comparison with the DRV. Although gaps in the compositional databases may have contributed to underestimates of intake in the two Scottish studies, this is less likely in the NDNS survey. The adequacy of $\mathrm{Zn}$ intakes, however, is difficult to establish because assessment of $\mathrm{Zn}$ status is unreliable and the DRV are probably generous (Department of Health, 1991). It seems plausible that the lower $\mathrm{Zn}$ intakes of the high NMES groups may be mitigated by a higher $\mathrm{Zn}$ bioavailability as a result of their lower NSP intakes (Table 4) (Wise, 1996).

For vitamin D, dietary sources are supplemented by endogenous synthesis in the skin on exposure to sunlight, and in recognition of this, there is no RNI for vitamin D for children aged 4 years and above. Vitamin D intakes in the present study, whilst low in comparison with the RNI, were considerably higher than those in the study by Payne \& Belton (1992), possibly due to the use of improved data on food composition. There was no association with NMES concentration.

The inverse associations identified between NMES concentration and micronutrient intake have to be weighed against the possibly undesirable increase in percentage energy from fat that is seen at low NMES concentrations. This is a well-established reciprocal relationship (Department of Health and Social Security, 1989; Gibney, 1990; Ruxton et al. 1996; Gibson, 1996) and may be reason for caution in advocating a significantly reduced sugars consumption. There are differences of opinion on the age at which fat restriction can be safely implemented in early childhood, and these have recently been reviewed by 
Michaelsen \& Jorgensen (1995). However, current UK dietary guidelines suggest that by the age of 5 years children should be consuming a diet consistent with the recommendations for adults (i.e. about $35 \%$ of energy from fat; Department of Health, 1994). In the present study, children with NMES intakes in the 3rd and 4th quintiles (16$24 \%$ energy from NMES) had fat intakes closest to recommended levels (mean 34-36\% energy from fat). Replacement of whole milk by semi-skimmed milk would go some way to reducing proportional fat intake, and its range across NMES quintiles. However, simultaneously achieving the dietary targets for fat (35\% energy) and NMES (10\% energy) is difficult, even for adults (Gibney, 1990). In young children, the concomitant reduction in energy density could potentially compromise growth in some, especially in the presence of infection, or low meal frequency (Michaelsen \& Jorgensen, 1995). More research is needed in this area, but some compromise over the target for NMES energy (currently $10 \%$ of total energy) would appear to be warranted for this age group.

Finally, the adequacy of micronutrient intakes is more strongly dependent on energy intakes than on sugars concentration (Department of Health and Social Security, 1989). The present study has demonstrated that, for a normal pre-school population, the impact of nutrient dilution by NMES is small below about $20 \%$ of energy from NMES. In relation to DRV, nutrient dilution by NMES has more importance for those children (about one in five) who consume very high-NMES diets ( $>24 \%$ NMES-energy). However, further work that incorporates markers of nutrient status is required to establish to what extent these observed effects on micronutrient intakes have true biological significance.

\section{CONCLUSIONS}

For all nutrients, except vitamin $\mathrm{C}$, a downward trend in micronutrient intakes was observed with increasing NMES concentration. However, the diets of children in this study were more than adequate for most micronutrients $(\mathrm{Ca}$, thiamin, riboflavin, niacin, folate, and vitamin $\mathrm{C}$ ). Intakes of a few specific nutrients, notably $\mathrm{Fe}, \mathrm{Zn}$ and vitamin $\mathrm{D}$, were below the RNI at all levels of NMES energy. For Fe, the most marginal nutrient, and for $\mathrm{Zn}$ also, mean intakes fell below the EAR in the 5th quintile. Overall, in these children, the effect of NMES on micronutrient intakes would appear to be of minor significance up to $20 \%$ of energy from NMES and of most significance in children with diets supplying $>24 \%$ of energy from NMES.

Data from the National Diet and Nutrition Survey of Children aged 1.5 to 4.5 years, made available through the Office of Population Censuses and Surveys, the Ministry of Agriculture, Fisheries and Food and the Department of Health, and the ESRC Data Archive, has been used by permission of the Controller of H.M. Stationery Office. The author acknowledges the financial support of the Sugar Bureau.

\section{REFERENCES}

Bolton-Smith, C. \& Woodward, M. (1994). Dietary composition and fat to sugar ratios in relation to obesity. International Journal of Obesity 18, 820-828.

Department of Health and Social Security (1975). A Nutrition Survey of Pre-schoolchildren 1967-1968. Report on Health and Social Subjects no. 10. London: H. M. Stationery Office.

Department of Health and Social Security (1989). Dietary Sugars and Human Disease. Report on Health and Social Subjects no. 37. London: H. M. Stationery Office.

Department of Health (1991). Dietary Reference Values for Food Energy and Nutrients for the United Kingdom. Report on Health and Social Subjects no. 41. London: H. M. Stationery Office. 
Department of Health (1994). Nutrition Aspects of Cardiovascular Disease. Report on Health and Social Subjects no. 46. London: H. M. Stationery Office.

Gibney, M. J. (1990). Dietary guidelines: a critical appraisal. Journal of Human Nutrition and Dietetics 3, 245254.

Gibney, M., Sigman-Grant, M., Stanton, J. L. Jr \& Keast, D. R. (1995). Consumption of sugars. American Joumal of Clinical Nutrition 62, Suppl. 1, 178S-194S.

Gibson, S. A. (1993). Consumption and sources of sugars in the diets of British schoolchildren. Journal of Human Nutrition and Dietetics 6, 355-371.

Gibson, S. A. (1996). Are high-fat, high-sugar foods and diets conducive to obesity? International Journal of Food Sciences and Nutrition 47, 405-415.

Gibson, S. A. (1997). Do high sugar diets compromise micronutrient intakes? Journal of Human Nutrition and Dietetics 10, 125-133.

Gregory, J., Foster, K., Tyler, H. \& Wiseman, M. (1990). The Dietary and Nutritional Survey of British Adults. London: H. M. Stationery Office.

Gregory, J. R., Collins, D. L., Davies, P. S. W., Hughes, J. \& Clarke, P. (1995). National Diet and Nutrition Survey: Children Aged 1.5 to 4.5 Years. Vol. 1. Report of the Diet and Nutrition Survey. London: H. M. Stationery Office.

Michaelsen, K. F. \& Jorgensen, M. H. (1995). Dietary fat content and energy density during infancy and childhood: the effect on energy intake and growth. European Journal of Clinical Nutrition 49, 467-483.

Naismith, D. J., Nelson, M., Burley, V. \& Gatenby, S. (1995). Does a high sugar diet promote overweight in children and lead to nutrient deficiencies? Journal of Human Nutrition and Dietetics 8, 249-254.

Nelson, M., Naismith, D. J., Burley, V., Gatenby, S. \& Geddes, N. (1990). Nutrient intakes, vitamin-mineral supplementation, and intelligence in British schoolchildren. British Journal of Nutrition 64, 13-22.

Payne, J. A. \& Belton, N. R. (1992). Nutrient intake and growth in pre-school children. II. Intake of minerals and vitamins. Journal of Human Nutrition and Dietetics 5, 299-304.

Rugg-Gunn, A. J., Hackett, A. F., Jenkins, G. N. \& Appleton, D. R. (1991). Empty calories? Nutrient intake in relation to sugar intake in English adolescents. Journal of Human Nutrition and Dietetics 4, 101-111.

Ruxton, C. H. S., Kirk, T. R., Belton, N. R. \& Holmes, M. A. M. (1996). Energy and nutrient intakes in a sample of 136 Edinburgh 7-8 year olds: a comparison with United Kingdom dietary reference values. British Journal of Nutrition $\mathbf{7 5}, 151-160$.

Wise, A. (1996). Phytate and zinc bioavailability. International Journal of Food Sciences and Nutrition 46, $53-$ 63. 